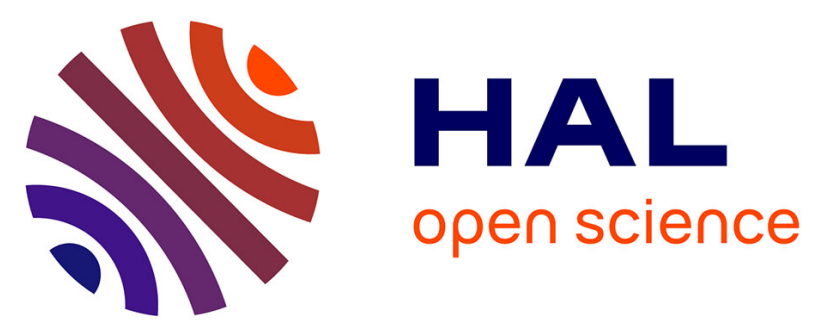

\title{
The 3rd workshop on sediment dynamics of muddy coasts and estuaries: An introduction and synthesis
} Xiao Hua Wang, Fei Chai, Lulu Qiao, Isabel Jalón-Rojas, Houjie Wang, Ya Ping Wang

\section{- To cite this version:}

Xiao Hua Wang, Fei Chai, Lulu Qiao, Isabel Jalón-Rojas, Houjie Wang, et al.. The 3rd workshop on sediment dynamics of muddy coasts and estuaries: An introduction and synthesis. Estuarine, Coastal and Shelf Science, 2020, 245, pp.106994. 10.1016/j.ecss.2020.106994 hal-03438456

\section{HAL Id: hal-03438456 https://hal.science/hal-03438456}

Submitted on 21 Nov 2021

HAL is a multi-disciplinary open access archive for the deposit and dissemination of scientific research documents, whether they are published or not. The documents may come from teaching and research institutions in France or abroad, or from public or private research centers.
L'archive ouverte pluridisciplinaire HAL, est destinée au dépôt et à la diffusion de documents scientifiques de niveau recherche, publiés ou non, émanant des établissements d'enseignement et de recherche français ou étrangers, des laboratoires publics ou privés.

\section{다(1)(2)}

Distributed under a Creative Commons Attribution - ShareAlikel 4.0 International 


\section{Manuscript Details}

Manuscript number

Title

Article type

Keywords

Taxonomy

Corresponding Author

Corresponding Author's

Institution

Order of Authors
ECSS_2020_428

The 3rd Workshop on Sediment Dynamics of Muddy Coasts and Estuaries: an Introduction and Synthesis

Editorial

Sediment dynamics; Muddy coasts; Estuaries; Synthesis; Workshop

Coastal Ecohydrology, Oceanography

Xiao Hua Wang

UNSW

Xiao Hua Wang, Fei Chai, Lulu Qiao, Isabel Jalón-Rojas, Houjie Wang, Ya Ping Wang

\section{Submission Files Included in this PDF}

File Name [File Type]

Highlights_ECSS.docx [Highlights]

Wang et al edtitorial-Ready to submit.docx [Manuscript File]

CoverLetter_ECSS.docx [Conflict of Interest]

To view all the submission files, including those not included in the PDF, click on the manuscript title on your EVISE Homepage, then click 'Download zip file'.

\section{Research Data Related to this Submission}

There are no linked research data sets for this submission. The following reason is given:

No data was used for the research described in the article 


\section{The $3^{\text {rd }}$ Workshop on Sediment Dynamics of Muddy Coasts and Estuaries: an Introduction and Synthesis}

\section{Highlights}

The workshop series on sediment dynamics of muddy coasts and estuaries focused on international frontier issues and major social needs, such as land-sea interactions, estuarine and coastal monitoring, numerical simulation, sediment transport and its biogeochemical effects. The Third Workshop was held in Qingdao, China, in November 2018, hosted by the Institute of Estuarine and Coastal Studies, Ocean University of China. As a result of the Third Workshop, this special issue contains 18 papers with case studies of muddy coasts in the Bohai, Yellow and East China Seas in China and other regions worldwide. 


\title{
The $3^{\text {rd }}$ Workshop on Sediment Dynamics of Muddy Coasts and Estuaries: an Introduction and Synthesis
}

\begin{abstract}
The workshop series on sediment dynamics of muddy coasts and estuaries focused on international frontier issues and major social needs, such as land-sea interactions, estuarine and coastal monitoring, numerical simulation, sediment transport and its biogeochemical effects. The Third Workshop was held in Qingdao, China, in November 2018, hosted by the Institute of Estuarine and Coastal Studies, Ocean University of China. As a result of the Third Workshop, this special issue contains 18 papers with case studies of muddy coasts in the Bohai, Yellow and East China Seas in China and other regions worldwide. These papers represent the most recent advances in Chinese and international estuarine and coastal sediment research in the topics including 1) In-situ observations of sediment dynamics in muddy coasts and estuaries and satellite remote sensing; 2) Modelling of sediment transport and associated sedimentary processes; 3) Fluid mud transport and process in bottom boundary layer, and 4) Blue bay remediation action plan and coastal restoration.
\end{abstract}

Keywords: Sediment dynamics; Muddy coasts; Estuaries; Synthesis; Workshop

\section{Introduction}

The workshop series on sediment dynamics of muddy coasts and estuaries focused on international frontier issues and major social needs, such as land-sea interactions, estuarine and coastal monitoring, numerical simulation, sediment transport and its biogeochemical effects. The First Workshop was held in Guilin, China, in September 2009 and was hosted by the State Key Laboratory of Satellite Ocean Environment Dynamics, Second Institute of 
Oceanography, State Oceanic Administration, China. The Second Workshop was held in Zhoushan, China, in October 2015 hosted by Ocean College, Zhejiang University. Based on the success of the previous two workshops, the Third Workshop was held in Qingdao, China, in November 2018, hosted by the Institute of Estuarine and Coastal Studies, Ocean University of China in order to 1) review progress since the previous workshops; 2) strengthen and expand the network of the coastal research community including young scientists and encourage multi-disciplinary as well as international collaborations; and 3) further identify new research themes (e.g., marine microplastics and debris) and formulate current and future scientific questions and national/societal needs (e.g., coastal remediation and restoration).

As a result of the Third Workshop, this special issue contains 18 papers with case studies of muddy coasts in the Bohai, Yellow and East China Seas in China and other regions worldwide. These papers represent the most recent advances in Chinese and international estuarine and coastal sediment research in the following themes: 1) In-situ observations of sediment dynamics in muddy coasts and estuaries and satellite remote sensing (Chang et al., 2020; Duan et al., 2020; Li et al., 2020; Liu et al., 2020; Niu et al., 2020; Qiao et al., 2020; Z. Wang et al., 2020a and Zhong et al, 2020); 2) Modelling of sediment transport and associated sedimentary processes (Cruz and Noernberg, 2020; Tran and Strom, 2020; D. Wang et al., 2020 and Xiao et al., 2020); 3) Fluid mud transport and process in bottom boundary layer (Peng et al., 2020; Tang et al., 2020; Xue et al., 2020 and Xu et al., 2020), and 4) Blue bay remediation action plan and coastal restoration (A. Wang et al., 2020 and Zhu et al., 2020). The papers that address these themes are discussed in next section.

\section{Main themes in this SI}




\section{Theme 1: In-situ observations of sediment dynamics in muddy coasts and estuaries and satellite remote sensing}

Zhong et al. (2020) investigated the sediment trapping in a typical coastal embayment using Weihai Bay, China, as an example. The study is based on observations of water depths, current profiles, wave parameters, near-bed flow velocities, turbidity, salinity and temperature. Shear stresses, residual currents and suspended sediment fluxes at the nearbottom were calculated. The authors concluded that, in the northern mouth, the temporal variability of suspended sediment concentration (SSC) was controlled by local resuspension, whereas in the southern mouth is due to the advection of a horizontal SSC gradient. The sediment trapping occurs mainly through the southern mouth and extends further landward through tidal pumping. The embayment tends to import fine sediments from the shelf at residual time scales. In two different papers, the suspended sediment in the continental shelves of China was investigated, using the method of remote sensing and in-situ measurements (Li et al., 2020 and Qiao et al., 2020). They provided a general pattern of suspended sediment concentration from the East China Sea to the Yellow Sea, with some discussion on the mechanisms of fine sediment transport from nearshore to the shelves. For example, Qiao et al. (2020) derived the spatiotemporal variations of SSC from MODIS during 2003-2018, and found that the wind is the controlling factor that affects the SSC in most areas in the Zhe-Min coast, especially in the spring and winter seasons. Their study concluded that the SSC anomaly exhibits opposite phases between the north and south parts of $28-29^{\circ} \mathrm{N}$ and between the landside and seaside of the front at the isobaths of $20 \mathrm{~m}$ to $40 \mathrm{~m}$ along the Zhe-Min Coast.

\section{Theme 2: Modelling of sediment transport and associated sedimentary processes}

D. Wang et al. (2020) investigated the data assimilation of multi-source SSC observations 


\section{Theme 3: Fluid mud transport and process in bottom boundary layer}

Based on the field observations off the Changjiang estuary, China, Peng et al. (2020) pointed out that the flow structures within the bottom layer could be prominently influenced when the gradient of SSC reaches a value in order of $0.1 \mathrm{~kg} \mathrm{~m}^{-4}$. Moreover, modification of the flow structure diminishes with the depth, and the drag coefficient reduction induced by sediment stratification is depth-dependent. In another study, a series of entrainment and sedimentation experiments was performed in an annular flume (Xu et al., 2020). The authors demonstrated that the settling rate of fluid mud sample with higher salinity is enhanced and the gelling 


\section{Theme 4: Blue bay remediation action plan and coastal restoration}

Wang et al. (2020) focused on the sedimentary processes in the subaqueous deltas of a typical small mountainous river, Mingjiang, in the southern East China Sea based on a short sediment core. They concluded that the increased sediment flux since 1960s delivered to the sea by Minjiang was caused by the change of land use pattern and intensified soil erosion. Then a decreased sedimentation rate in the river delta since the 1980s was resulted from the reservoir construction. Their work provides data for assessing the impact of human activities on the sedimentary environment in small estuaries. Zhu et al. (2020) studied management of drainage pipes to optimize beach nourishment. The 'salient' landform is explored as a feasible plan that considers beach nourishment and breakwater geometry of the drainage pipe outlets. Using the XBeach simulations, the study found that the seaward convex breakwater layout is the most effective option among three typical breakwater layouts (straight, landward convex, and seaward convex), as it can accumulate the largest volume of sediment behind the structure.

\section{Discussion and conclusions}

One of the key debates during the Third Workshop amounted to a call for the urgent development of a science-based indicator framework to evaluate the Blue Bay Remediation Project (BBRP, Wang and Wang, 2018). The State Oceanic Administration of China 
There were only presentations on the theme of Microplastics transport and modelling scheduled as a separate session during the Third Workshop. Unfortunately neither of these presentations made it to publication in this SI. Marine plastic debris is critical environmental issues affecting the world today. Numerical modelling is one of the key tools to understand and estimate the sources, trajectories and fate of marine debris, especially microplastics. In the session keynote speech entitled 'Modelling the transport of microplastics in coastal and marine environments: a new approach', the presenter introduced the TrackMPD modelling framework as a new approach for the transport of marine plastic debris (Jalón-Rojas et al., 2019). TrackMPD fills the gaps of previous models by (1) considering a three-dimensional approach, (2) providing compatibility with a variety of ocean models, and (3) including a wide range of physical processes (advection, dispersion, wind age, sinking, settling, beaching 
and re-floating) and MPD behaviour according to the particle dynamical properties, and the fouling and degradation state.

There were in total more than 200 participants who represented 39 institutions mostly from China, from multi-disciplinary fields. They include students and postdocs (42.5\%), early- to mid-career researchers (32.5\%) and professorial and other senior scientists $(25 \%)$. The Workshop noted that there were significant representations from several emerging Oceanography Schools in China such as Zhejiang University, Hohai University and Sun Yatsen University. This reflects an interesting trend that coastal and estuarine research has been increasingly taken up by these non-traditional Oceanographic institutions over the past 15 years. The Third Workshop also attracted overseas scientists from University of Auckland, New Zealand, UNSW Australia, Institution of coastal Research, HZG, Germany and University of Hull, UK.

The Third Workshop was kindly sponsored by the Laboratory of Marine Geology, Pilot National Laboratory for Marine Science and Technology (Qingdao); Key Laboratory of Submarine Geosciences and Prospecting Techniques, Ministry of Education, Ocean University of China; the Coast and Estuary Branch of Chinese Society for Oceanography; the Sino-Australian Research Centre for Coastal Management, UNSW Canberra, Australia; the State Key Laboratory of Estuarine and Coastal Research, East China Normal University. We wish to thank our host, Professor Houjie Wang, and scientists and staff of the Ocean University of China for their warm hospitality and support during the workshop. XHW wishes to thank Professor Lulu Qiao and her team in particular for their tireless effort in organizing the workshop. 


\section{References}

Yang Chang, Yining Chen, Ya Ping Wang, 2020. Field measurements of tidal flows affected by mangrove seedlings in a restored mangrove swamp, Southern China. Estuarine, Coastal and Shelf Science, In press

Guilherme Cruz, Mauricio Noernberg, 2020. Bedforms controlled by residual current vortices in a subtropical estuarine tidal channel. Estuarine, Coastal and Shelf Science, In press

Haiqin Duan, Chenghao Wang, Zhiqiang Liu, Houjie Wang, Xiao Wu, Jingping Xu, 2020. Summer wind gusts modulate transport through a narrow strait, Bohai, China. Estuarine, Coastal and Shelf Science, In press

I. Jalón-Rojas, X.H. Wang and E. Fredj, 2019, A 3D numerical model to Track Marine Plastic Debris (TrackMPD): sensitivity of microplastics trajectories and fate to particle dynamical properties and physical processes, Marine Pollution Bulletin, 141, 256-272.

Wenjian Li, Zhenyan Wang, Haijun Huang, 2020, Indication of Size Distribution of Suspended Particulate Matter for Sediment Transport in the South Yellow Sea. Estuarine, Coastal and Shelf Science, In press

Xingmin Liu, Lulu Qiao, Yi Zhong, Xiuquan Wan, Wenjing Xue, Peng Liu, 2020. Pathways of suspended sediments transported from the Yellow River mouth to the Bohai Sea and Yellow Sea. Estuarine, Coastal and Shelf Science, In press

Jianwei Niu, Jishang Xu, Guangxue Li, Ping Dong, Jinghao Shi, Lulu Qiao, 2020. Swell-dominated sediment resuspension in a silty coastal seabed. Estuarine, Coastal and Shelf Science, In revision.

Yun Peng, Qian Yu, Yang Yang, Yunwei Wang, Ya Ping Wang, Shu Gao, 2020. Flow structure modification and drag reduction induced by sediment stratification in coastal tidal bottom boundary layers. Estuarine, Coastal and Shelf Science, In press

Lulu Qiao, Shidong Liu, Wenjing Xue, Peng Liu, Rijun Hu, Huifeng Sun, Yi Zhong, 2020. Spatiotemporal variations in suspended sediments over the inner shelf of the East China Sea with the effect of oceanic fronts. Estuarine, Coastal and Shelf Science, In press.

Jieping Tang, Ya Ping Wang, Qingguang Zhu, Jianjun Jia, Jilian Xiong, Peng Cheng, Hui Wu, Dezhi Chen, Hao Wu, 2020. Winter storms induced high suspended sediment concentration along the north offshore seabed of the Changjiang Estuary. Estuarine, Coastal and Shelf Science, In press

Duc Tran, Kyle Strom, 2020. Floc sizes and resuspension rates from fresh deposits: influences of suspended sediment concentration, turbulence and deposition time. Estuarine, Coastal and Shelf Science. In press.

Aijun Wang, Xiang Ye, Zhenkun Lin, Liang Wang, Jing Lin, 2020, Response of sedimentation processes in the Minjiang River subaqueous delta to anthropogenic activities in the river basin. Estuarine, Coastal and Shelf Science, In press

Daosheng Wang, Jicai Zhang, Xinyan Mao, Changwei Bian, Zhou Zhou, 2020, Simultaneously assimilating multi-source observations into a three-dimensional suspended cohesive sediment transport model by the adjoint method in the Bohai Sea. Estuarine, Coastal and Shelf Science, In press. 
M. Wang and X. H. Wang, 2018, Introduction to the National Blue Bay Remediation Action Plan in China, Australian Journal of Maritime \& Ocean Affairs, https://doi.org/10.1080/18366503.2018.1534522

Zhiwen Wang, Chenghao Wang, Fukang Qi, Haiqin Duan, Jingping Xu, 2020. Observations of internal tides off the coast of Shandong peninsula, China. Estuarine, Coastal and Shelf Science, In revision

Cheng Xue, Tinglu Zhang, Shuguo Chen, Xiao Wu, Fengqi Yan, 2020. A novel estimation method for SPM in China eastern coastal waters based on conventional hydrological profile measurements. Estuarine, Coastal and Shelf Science, In press.

Chunyang Xu, Yongping Chen, Yi Pan, Lili Yu, 2020. The effects of flocculation on the entrainment of the fluid mud layer. Estuarine, Coastal and Shelf Science, In press.

Z. Y. Xiao, X. H. Wang, D. Song, I. Jalón-Rojas and D. Harrison, 2020. Numerical modelling of suspended-sediment transport in a geographically complex microtidal estuary: Sydney Harbour Estuary, NSW. Estuarine, Coastal and Shelf Science, https://doi.org/10.1016/j.ecss.2020.106605

Wei Zhong, Longhai Zhu, Ping Dong, Rijun Hu, Jianzheng Wu, Yingtao Zhu, Haiqin Duan, 2020. Mechanisms of sediment trapping in coastal embayments off the Shandong Peninsula in summer-A case study in Weihai Bay. Estuarine, Coastal and Shelf Science, In press

Jun Zhu, Feng Cai, Fengyan Shi, Hongshuai Qi, Gang Lei, Jianhui Liu, Huimei Cao, Jixiang Zheng, 2020. Beach response to breakwater layouts of drainage pipe outlets during beach nourishment.

Estuarine, Coastal and Shelf Science, In press

Xiao Hua Wang* The Sino-Australian Research Centre for Coastal Management, UNSW Canberra, Canberra, ACT, 2600, Australia

Fei Chai State Key Laboratory of Satellite Ocean Environment Dynamics, Second Institute of Oceanography, Ministry of Natural Resources, China Institute of Estuarine and Coastal Zone, Ocean University of China

Isabel Jalón-Rojas

UMR 5805 EPOC, Centre National de la Recherche Scientifique, Pessac, France The Sino-Australian Research Centre for Coastal Management, UNSW Canberra, Canberra, ACT, 2600, Australia

Houjie Wang College of Marine Geosciences, Ocean University of China

Ya Ping Wang State Key Laboratory of Estuarine and Coastal Research, East China Normal University

*Corresponding author. E-mail address: x.h.wang@unsw.edu.au (X.H. Wang) 